Research Group: Public Economics

March 26, 2009

\title{
Why is Law Enforcement Decentralized?
}

GUILLAUME CHEIKBOSSIAN AND NICOLAS MARCEAU 


\section{Why Is Law Enforcement Decentralized ?^}

\section{Guillaume Cheikbossian}

Toulouse School of Economics (GREMAQ)

Nicolas Marceau

Université du Québec à Montréal and CIRPÉE

March 26th, 2009

Cheikbossian: guillaume.cheikbossian@univ-tlse1.fr

Marceau: marceau.nicolas@uqam.ca

For their useful comments and suggestions, we would like to thank Marcelin Joanis, Alessandro Riboni, Al Slivinski, seminar participants at Queen's University, Royal Military College in Kingston, Université de Paris X Nanterre, Université de Rennes, and conference participants at the 2008 Econometric Society European Meeting and at the 2008 meeting of the Société Canadienne de Science Économique. Financial support from the FQRSC and the SSHRCC is gratefully acknowledged. 


\begin{abstract}
Law enforcement is decentralized. It is so despite documented interjurisdictional externalities which would justify its centralization. To explain this fact, we construct a political economy model of law enforcement. Under decentralization, law enforcement in each region is in accord with the preferences of regional citizens, but interjurisdictional externalities are neglected. Under centralization, law enforcement for all regions is chosen by a legislature of regional representatives which may take externalities into account. However, the majority rule applies for decisions made by the central legislature and this implies that the allocation of enforcement resources may be skewed in favour of those who belong to the required majority. We show that the choice between centralization and decentralization depends on the technology of law enforcement and the nature of the interjurisdictional externalities.
\end{abstract}

Keywords: Crime; Law enforcement; Decentralization; Externalities

JEL Classification: K42 


\section{Introduction}

In several countries, a significant portion of law enforcement is undertaken at the local level. As reported in Table 1, in Canada, $57 \%$ of expenditures on police protection were made at the local level in 2005 , and $58.8 \%$ of police forces worked at that same level in 2006 . For the USA, the numbers in Table 2 point to even more decentralization. Indeed, in 2003, $64.6 \%$ of expenditures on police protection were made at the local level and $76.5 \%$ of police forces worked at that level. Why such an arrangement? Why is police protection, and more generally law enforcement, left in the hands of local authorities? Given that the decentralization of law enforcement is not without problems, this phenomenon certainly requires an explanation.

\section{- TABLE 1 HERE - \\ - TABLE 2 HERE -}

When law enforcement increases, criminals may react in a variety of manners. Of course, criminals may simply decide not to commit a crime, which is the ideal outcome from the perspective of the authorities. But things are unfortunately not so simple and criminals can also adapt to new circumstances. For instance, when increased enforcement takes place at a specific time (e.g. curfew), criminals may decide to operate at a different time, a phenomenon labeled temporal displacement. ${ }^{1}$ Criminals may also change target, method, and type of crime. More importantly for us, when increased enforcement is targeted at a specific area, criminals may decide to operate in a different location, a phenomenon labeled spatial displacement, which is in fact a standard negative externality. The nature and the size of spatial displacement is debated among criminologists, but many believe it has to be taken into account in the design of law enforcement policies. ${ }^{2}$ On the other hand, some criminologists argue that the benefits of enforcement in a specific location may actually diffuse to nearby locations in which criminality is reduced. ${ }^{3}$ In such case, the externality of enforcement would be positive.

To understand how enforcement can lead to displacement and/or diffusion, suppose that the authorities, hoping to reduce crime in a specific neighbourhood, have chosen to increase the presence of the police in, say, street A. In one scenario, suppose that criminals know that the increased presence is taking place exclusively in street A, and not in other streets. In such a case, it is obvious that the criminals can avoid the intensified enforcement by moving their criminal activities to any

\footnotetext{
${ }^{1}$ Jacob et al. (2004) argue that in the short run, there is substantial displacement of crime over time.

${ }^{2}$ See Bowers and Johnson (2003) for an interesting discussion of the issues.

${ }^{3}$ For example, see Weisburd et al. (2006).
} 
street but A. Thus, when criminals are well informed regarding the location of increased enforcement, displacement is the likely outcome while diffusion is unlikely. But consider the alternative scenario in which criminals know that more enforcement is taking place, but do not know the specific streets in which enforcement resources are larger. For example, this could happen when strengthened enforcement is in the form of an increase in the number of police patrols taking place in unidentified cars. In such a case, criminals may assign an increased probability of being caught by the police when operating in any street of the neighbourhood - street A as well as the other streets. As a consequence, criminal activity may go down in all streets of the neighbourhood, not only in street A. Thus, when criminals are not well informed regarding the location of increased enforcement, diffusion is a realistic possibility while displacement is less likely. As this example shows, whether displacement or diffusion takes place depends on the specific environment (e.g. what criminals know, whether enforcement is observable, etc...) in which enforcement is taking place. ${ }^{4}$

In our analysis, there are two regions which may undertake law enforcement. We remain agnostic as to whether law enforcement entails spatial displacement or diffusion of its benefits, from one region to the other. Both possibilities are allowed for in our modeling. However, we note that provided law enforcement entails displacement or diffusion, then it is likely that there would be benefits to its centralization as a central authority could internalize negative - spatial displacement and positive - diffusion of benefits - externalities between regions. Of course, the internalization of externalities would justify centralization if governments behaved as benevolent dictators and were allowed to set differentiated levels of enforcement for each region. However, from a political economy perspective, the operation of centralized systems may be inefficient. This is because, under centralization, sharing the costs of local public spending gives rise to a distributive conflict as each region wishes to push the central government for an expansion of its own public sector level. This conflict of interests plays out in the political arena, taking the specific form of a legislative process, as is typically the case in centralized systems.

More precisely, we consider a three-stage policy game. In the first stage, voters in each region decide by majority voting, whether decisions on crime enforcement are to be decentralized or centralized. In the second stage, voters in each region elect also by majority voting a representative. Finally, in the third stage, the regional representatives simultaneously choose the level of law enforcement for their own region in case citizens voted for decentralization in the first stage of the game. If however they voted for centralization, then the representatives seat in the central legislature

\footnotetext{
${ }^{4}$ In particular, note that diffusion — caused by criminals being imperfectly informed — between two regions is a realistic possibility under centralization, but less so under decentralization. This is because under decentralization, it is understood that enforcement expenditures of region $i$ will be undertaken exclusively within the frontiers of region $i$. But there are other mechanisms that can lead to diffusion, even under decentralization. One such mechanism occurs when individuals make the decisions of becoming criminals or remaining honest based on the average return to crime in all regions. In such a case, enforcement expenditures in region $i$ reduce the number of individuals who become criminals in all regions.
} 
to choose the levels of enforcement for the two regions. The majority rule in the central legislature makes possible the exploitation of a region outside of the majority. As will be seen, this possibility is the main weakness of centralization. ${ }^{5}$ On the other hand, no such problem will plague decentralized systems, but as already discussed, regional representatives will neglect externalities and this will lead to an inadequate allocation of resources. We are thus able to ascertain the conditions under which a society would make the choice of centralizing or decentralizing law enforcement. As the analysis shows, this depends on the technology of law enforcement, in particular, on the relative size of the parameters reflecting displacement and diffusion but also on the asymmetry in median wealth between the two regions.

There is a growing literature that analyzes enforcement externalities between individuals. ${ }^{6}$ But to our knowledge, the literature on the enforcement externalities between adjacent jurisdictions is more limited. Marceau (1997), Marceau and Mongrain (2007), Newlon (2001), and Teichman (2005) are the few analyzes that take into account the spatial displacement of crime between jurisdictions. However, none of them provide an explanation for the decentralization of law enforcement to local governments, an arrangement which makes it more likely for diffusion or displacement to take place. The current paper provides such an explanation by adopting a political economy perspective.

This paper is also related to the huge literature on fiscal (de)centralization. Traditionally, this literature describes centralization as a system in which a central authority chooses a uniform level of public good for each district and total public spending is financed from general revenues while decentralization is described as a system in which decisions are made by local governments and financed by local taxation. The choice between a centralized system and a decentralized system then depends on weighting the benefits of internalizing externalities with the costs of policy uniformity, a result known as Oates (1972) Decentralization Theorem. This trade-off is also at the heart of the recent literature on the political economy of the organization and size of governments. For example, Alesina and Spolaore (1997) consider a model where the number and size of nations is determined endogenously and depends on the trade-off between scale economies and the diversity of preferences regarding the provision of public goods. ${ }^{7}$ Bolton and Roland (1997) study a nation in which public policy must redistribute income between poor and rich agents. There are two unequally wealthy regions that favor different redistribution policies and they trade off the political gains of a redistribution policy closer to the preferences of the median voter in the region against an exogenous cost of disintegration. Other recent works, including Redoano and Scharf (2004) and Alesina et al. (2005) among others, analyze more sophisticated voting rules such as direct referendum or qualified

\footnotetext{
${ }^{5}$ On the functioning of legislatures, see also Ferejohn et al. (1987) and Lockwood (2002).

${ }^{6}$ Interesting examples include Glaeser et al. (1996), Hotte and Van Ypersele (2008), Kling et al. (2005), and Shavell (1991).

${ }^{7}$ In the same spirit, see also Ellingson (1998).
} 
majority voting. In all these studies, the relative benefits of centralization also depend on the internalization of the externalities while that on decentralization on the adaptability to regional differences. In our analysis, heterogeneity across jurisdictions has the same centripetal effect but is not necessary for decentralization to occur. We indeed show that decentralization can be preferred by a majority of voters even though the two regions are perfectly identical. This is because, under centralization, the majority rule gives rise to a political risk as each region is not certain that its representative will belong to the winning coalition.

Finally, there is the analysis by Besley and Coate (2003), to which our paper is closely related. They re-examined the basic trade-off between centralized and decentralized provision of local public goods by departing from standard assumption that centralized policy is uniform across heterogeneous localities. Instead, they consider that under centralization, policy is determined by a legislature of locally elected representatives that can differentiate the levels of public spending. They also specify two different types of legislative behavior. In one case, they assume that spending on local public goods are determined by a minimum winning coalition of representatives. In turn, this coalition can skew the allocation of public spending towards the localities they represent, to the detriment of the localities whose representatives are outside the coalition. In the other case, they consider that the legislature maximizes the surplus of all its members. This creates an incentive for voters in each region to strategically delegate to a representative with a strong preferences for public spending as it allows them to capture more of the common tax revenue for their own project. Both situations yield an inefficient outcome and the drawback from centralized decision-making is balanced with the benefits of internalizing (positive) externalities to determine which regime, between centralization and decentralization, performs better in terms of aggregate surplus. In the present analysis, we use the minimum winning coalition approach à la Besley and Coate to model centralized decisionmaking. However, our focus is on law enforcement policies which entail both positive as well as negative interjurisdictional externalities. In addition, and more importantly, our analysis is positive rather than normative. The objective of this paper is indeed to explain why law enforcement is often undertaken at the local level by carefully analyzing the outcome of a constitutional stage in which citizens in each region vote over the (de)centralization issue. In fact, all the results of this paper - stated as Propositions - are derived from the analysis of this initial stage, a stage which is not examined by Besley and Coate (2003).

This paper is organized as follows. In next section, we lay out the basic two-region model, and in particular, the technology of law enforcement. Section 3 examines the first best law enforcement policies that would be chosen by a benevolent dictator. In Section 4 , we examine the choice of law enforcement by elected governments under decentralization, while in Section 5 , we turn to the choice of law enforcement policies by a central government in which decisions are made by 
a legislature of elected regional representatives. The constitutional stage in which citizens choose between centralization and decentralization is examined in Section 6. This choice is shown to depend on the relative size of the parameters reflecting displacement and diffusion in the law enforcement technology. Section 7 provides further discussion and Section 8 offers some concluding remarks.

\section{The Model}

The economy is divided into two distinct regions indexed by $i \in\{1,2\}$. Under decentralization, there is a legislature in each region, while under centralization, there is a unique central legislature. Each region has a continuum of citizens of unit mass, so total population in the economy is of measure 2. Each citizen is endowed with some private income $x$, with $x$ distributed over the $[\underline{x}, \bar{x}]$ interval. The mean income in region $i$ is denoted by $m_{i}$, and we assume that $m_{i}$ also equals median income.

In each region, a proportion of the income of each voter is robbed by criminals. This proportion is equal to the number of criminals operating in region $i$ and is denoted by $c_{i}$. Therefore the amount of income that is left for consumption for an individual of type $x$ is $\left(1-c_{i}\right) x$. The number of criminals in region $i$ depends on the level of enforcement in the two regions, denoted by $\alpha_{i}$ for $i=\{1,2\}$. We assume an increasing marginal cost of enforcement. Specifically, we assume that to achieve a level of enforcement $\alpha_{i}$ in region $i$, it costs $\alpha_{i}^{2} / 2$. We also assume that a head tax (i.e. equal lump-sum tax) can be imposed on voters to finance expenditures in enforcement. Under decentralization, the level of enforcement $\alpha_{i}$ in region $i$ is chosen by the legislature of region $i$, and the cost is borne by the voters of region $i$ only. Since there is a unit mass of voters in region $i$, each voter bears a cost $\alpha_{i}^{2} / 2$. Under centralization, the central legislature makes the choice of enforcement levels $\left(\alpha_{1}, \alpha_{2}\right)$ for the two jurisdictions. The cost of achieving $\left(\alpha_{1}, \alpha_{2}\right)$ is then borne equally by the voters of the two regions so that each voter has to bear a cost of $(1 / 2)\left[\left(\alpha_{1}^{2} / 2\right)+\left(\alpha_{2}^{2} / 2\right)\right]=\left(\alpha_{1}^{2}+\alpha_{2}^{2}\right) / 4$.

Under decentralization, assuming region $i$ has chosen enforcement level $\alpha_{i}$, the welfare of a voter with income $x$ living in region $i$ is given by

$$
W_{i}=\left(1-c_{i}\right) x-\frac{1}{2} \alpha_{i}^{2}
$$

As for the situation under centralization, assuming enforcement levels $\alpha_{i}$ and $\alpha_{j}$ for region $i$ and region $j$, respectively, the welfare of a voter with income $x$ living in region $i$ is given by

$$
W_{i}=\left(1-c_{i}\right) x-\frac{1}{4}\left(\alpha_{i}^{2}+\alpha_{j}^{2}\right)
$$

We assume that the number of criminals operating in each region depends on the level of enforcement in both regions. We specifically assume:

$$
c_{i}\left(\alpha_{i}, \alpha_{j}\right)=\frac{1}{2}\left[1-a_{1} \alpha_{1}-a_{2} \alpha_{2}\right]-\gamma_{i}\left[\alpha_{i}-\alpha_{j}\right] ; \quad i \neq j .
$$


In this expression, $\gamma_{i} \geq 0$ is a parameter reflecting displacement which can also be interpreted as a mobility cost for criminals. When $\gamma_{i}=0$, mobility costs are infinite, no displacement occurs, and the two regions have half of the total number of criminals operating on their territory. If, however, $\gamma_{i}>0$, there is displacement and the number of criminals operating in region $i$ is decreasing in the difference between the levels of enforcement in the two regions (provided this difference is positive). In addition, the total number of criminals who operate in the two regions depends negatively on the levels of enforcement of the two regions, as happens when there is diffusion. The diffusion parameter $a_{i} \geq 0$ can be interpreted as a measure of the efficiency of the technology in deterring criminal activities. It could reflect the occupational choice of individuals who must choose between honest work and a criminal life, the return of the latter being reduced when any of the regions invest in enforcement. ${ }^{8}$ To clarify, for region $i$, the impact of increasing own enforcement $\alpha_{i}$ on the number of criminals operating on its territory $c_{i}$ is given by $\partial c_{i} / \partial \alpha_{i}=-a_{i} / 2-\gamma_{i}$, which is always negative. On the other hand, the impact of an increase in enforcement by the other jurisdiction $\alpha_{j}$ on $c_{i}$ is given by $\partial c_{i} / \partial \alpha_{j}=-a_{j} / 2+\gamma_{i}$. This last expression (of ambiguous sign) represents the external effect of law enforcement. In what follows, we assume, for simplicity, that $a_{1}=a_{2}=a$ and that $\gamma_{1}=\gamma_{2}=\gamma$. Therefore, from now on, $\gamma$ is the displacement parameter and $a$ is the diffusion parameter. Note that provided either $a$ or $\gamma$ is strictly positive, then $\partial c_{i} / \partial \alpha_{i}<0$ and jurisdictions always want to invest in enforcement because such an investment leads to a lower number of criminals on their territory. ${ }^{9}$

In this paper, one of our objective is to characterize the choice of enforcement of adjacent regions when decisions are made by elected governments (legislatures). We also would like to understand why it is commonly observed that crime enforcement is decentralized. Our characterization and our answer will be obtained by studying a three-stage game which can be described as follows.

1. Constitutional stage. Citizens in each of the two regions decide, by majority voting, whether decisions on crime enforcement are to be decentralized (i.e. left in the hands of regional legislatures) or centralized (i.e. made by a central legislature).

\section{Choice of representatives.}

\footnotetext{
${ }^{8}$ To keep the analysis simple, we use a reduced form approach and do not explicitly model occupational choice. On occupational choice, see, among many, Acemoglu (1995) or Sah (1991).

${ }^{9}$ Consider equation (3) which gives the number of criminals operating in region $i$ as a function of the level of enforcement in both regions. Note that a world without externality is one in which $a_{j}=\gamma_{i}=0$ so that equation (3) reduces to $c_{i}=(1 / 2)\left(1-a_{i} \alpha_{i}\right)$. In such a world, regions have an incentive to invest in enforcement and, provided regions have differing tastes or circumstances, Oates's Decentralization Theorem and the results of Besley and Coate (2003) would hold: Decentralization is preferred by the regions when there are no externalities. In equation (3), externalities are introduced by setting $a_{j} \neq 0$ and/or $\gamma_{i} \neq 0$. It should then be noted that one difficulty with assuming $a_{1}=a_{2}=a$ and $\gamma_{1}=\gamma_{2}=\gamma$, as we do, is that when we shut down the two externalities by imposing $a=\gamma=0$, we also shut down any motive the regions can have to invest in enforcement. We view this as a minor problem and we think that the gains in simplicity we obtain from our assumption are worth this cost.
} 
- Under Decentralization: Citizens in each region elect a representative to their regional legislature.

- Under Centralization: Citizens in each region elect a representative to the central legislature.

3. Choice of enforcement levels.

- Under Decentralization: The representatives from the two regional legislatures simultaneously choose the level of enforcement for their region.

- Under Centralization: The two representatives in the central legislature choose the levels of enforcement for the two regions.

In what follows, after examining the choices of a benevolent central government dictator, our benchmark, we will examine the last two stages of the above described games in which decision are either made by citizens or by elected representatives. We will examine these last two stages under decentralization in Section 4 and under centralization in Section 5. The constitutional stage will then be examined in Section 6, anticipating the results of Section 4 and 5 .

\section{The First Best Benchmark: Benevolent Central Govern- ment}

As our benchmark, we consider a benevolent central government dictator who can and will internalize the externalities and accommodate differences in incomes by imposing differentiated policies in each region. The first best levels of enforcement can be obtained by maximizing a utilitarian welfare function given by the sum of the voters' individual welfare or, given the assumed risk neutrality, by the sum of the mean voters' individual welfare, i.e. $\widetilde{W}=W\left(m_{1}\right)+W\left(m_{2}\right)$. For heuristic reasons, we assume that the sum of the costs of enforcement is borne equally by the voters of the two regions, i.e. each voter bears a cost $\left(\alpha_{1}^{2}+\alpha_{2}^{2}\right) / 4$, as in equation (2) above. Note that because of risk neutrality, the manner in which these costs are shared has obviously no impact on the optimal choice of $\left(\alpha_{1}, \alpha_{2}\right)$ by a benevolent central government.

The first-order conditions are given by:

$$
\begin{aligned}
-\frac{\partial c_{1}}{\partial \alpha_{1}} m_{1}-\frac{\partial c_{2}}{\partial \alpha_{1}} m_{2} & =\alpha_{1} \\
-\frac{\partial c_{1}}{\partial \alpha_{2}} m_{1}-\frac{\partial c_{2}}{\partial \alpha_{2}} m_{2} & =\alpha_{2}
\end{aligned}
$$

We obtain

$$
\begin{aligned}
& \widetilde{\alpha}_{1}=[0,5 a+\gamma] m_{1}+[0,5 a-\gamma] m_{2} \\
& \widetilde{\alpha}_{2}=[0,5 a-\gamma] m_{1}+[0,5 a+\gamma] m_{2}
\end{aligned}
$$


If we compare $\widetilde{\alpha}_{1}$ and $\widetilde{\alpha}_{2}$, we find that

$$
\widetilde{\alpha}_{1} \geqq \widetilde{\alpha}_{2} \text { as } m_{1} \underset{<}{<} m_{2}
$$

In other words, the optimal level of enforcement is higher in the richer region. Observe also that when $a \geq 2 \gamma$, both $\widetilde{\alpha}_{1}$ and $\widetilde{\alpha}_{2}$ are strictly positive independently of $m_{1}$ and $m_{2}$. Suppose now that $a<2 \gamma$ and that, for example, $m_{1}>m_{2}$. In this case, $\widetilde{\alpha}_{1}$ is strictly positive and $\widetilde{\alpha}_{2}$ is also strictly positive if and only if $m_{1} / m_{2}<(\gamma+0.5 a) /(\gamma-0.5 a)$. Hence, a benevolent central government optimally invests in deterrence activities in both regions if the median wealth asymmetry is not too strong, otherwise he/she does not invest in the poorer region (providing that negative investment is not possible). In this paper, we will assume throughout that if $a<2 \gamma$ and $m_{i}>m_{j}$ then $m_{i} / m_{j}<(\gamma+0.5 a) /(\gamma-0.5 a)$ which implies that the first best levels of investment in deterrence activities both in the richer and in the poorer regions are strictly positive.

In addition, the equilibrium numbers of criminals in the two regions are

$$
\begin{aligned}
c_{1}\left(\widetilde{\alpha}_{1}, \widetilde{\alpha}_{2}\right) & =\frac{1}{2}\left[1-a^{2}\left(m_{1}+m_{2}\right)\right]-2 \gamma^{2}\left(m_{1}-m_{2}\right), \\
c_{1}\left(\widetilde{\alpha}_{1}, \widetilde{\alpha}_{2}\right) & =\frac{1}{2}\left[1-a^{2}\left(m_{1}+m_{2}\right)\right]-2 \gamma^{2}\left(m_{2}-m_{1}\right) .
\end{aligned}
$$

Assume that region 1 is richer than region 2, i.e. $m_{1}>m_{2}$. In this case, $c_{1}<c_{2}$, i.e. the number of criminals who operate in region 1 is lower than that in region 2. This is because the marginal benefit of enforcement is larger in the richer region than in the poorer region whereas the marginal cost is independent of regions' wealth. Hence, it is optimal to invest more in enforcement in region 1 than in region 2 which in turn implies a lower number of criminals in region 1.

We now turn to the determination of welfare levels under optimal policies. The welfare of region $i$ when first best policies are in place is

$$
W_{i}=\left[1-c_{i}\left(\widetilde{\alpha}_{1}, \widetilde{\alpha}_{2}\right)\right] m_{i}-\frac{\left[\widetilde{\alpha}_{1}\right]^{2}+\left[\widetilde{\alpha}_{2}\right]^{2}}{4}
$$

We then find

$$
\begin{aligned}
\widetilde{W}_{1}= & {\left[0,5+a^{2}\left(m_{1}+m_{2}\right)+2 \gamma^{2}\left(m_{1}-m_{2}\right)\right] m_{1} } \\
& -\frac{1}{4}\left[\left(0,5 a^{2}+2 \gamma^{2}\right)\left(m_{1}^{2}+m_{2}^{2}\right)+\left(a^{2}-4 \gamma^{2}\right) m_{1} m_{2}\right], \\
\widetilde{W}_{2}= & {\left[0,5+a^{2}\left(m_{1}+m_{2}\right)+2 \gamma^{2}\left(m_{2}-m_{1}\right)\right] m_{2} } \\
& -\frac{1}{4}\left[\left(0,5 a^{2}+2 \gamma^{2}\right)\left(m_{1}^{2}+m_{2}^{2}\right)+\left(a^{2}-4 \gamma^{2}\right) m_{1} m_{2}\right] .
\end{aligned}
$$

Welfare is higher for the richer region than for the poorer one for two reasons. First, more wealth directly translates into more welfare. Second, the richer region benefits from a larger level of 
enforcement and a lower crime rate than the poorer region, while it pays only for the average cost of enforcement in the two regions.

Having established our benchmark, we now turn to the analysis of the last two stages of our threestage game with citizens and representatives as decision-makers. We first consider decentralization.

\section{Decentralization with Elected Governments}

Under decentralization, the choice of enforcement in region $i$ is made by its regional legislature. This regional legislature is assumed to be composed of a single representative chosen by and amongst the voters of the region. Thus, we have a two-stage policy game to solve. In the first stage, voters in each region elect a representative by majority rule. In the second stage, the representatives in each regional legislature simultaneously choose the level of enforcement for their region.

\subsection{Enforcement Levels}

As usual, we work backward. Let the types of the elected representatives in region 1 and 2 be $x_{1}$ and $x_{2}$, respectively. Each representative then decides the optimal level of enforcement given the other representative's policy choice. For the representative of region $i$, the first-order condition is

$$
-\frac{\partial c_{i}}{\partial \alpha_{i}} x_{i}-\alpha_{i}=0
$$

We can solve for the Nash equilibrium and obtain

$$
\alpha_{i}\left(x_{i}\right)=[0,5 a+\gamma] x_{i}
$$

This equilibrium level is increasing in $x_{i}, a$ and $\gamma$. The equilibrium number of criminals in region $i$ is then

$$
c_{i}\left(\alpha_{i}, \alpha_{j}\right)=\frac{1}{2}\left[1-a(0,5 a+\gamma)\left(x_{1}+x_{2}\right)\right]-\gamma(0,5 a+\gamma)\left(x_{i}-x_{j}\right) ; \quad i \neq j
$$

Hence, in a decentralized equilibrium, if the representative of region $i$ is richer than that of region $j$, then the level of enforcement is higher in region $i$ than in region $j$, which in turn induces a lower number of criminals in region $i$.

\subsection{Choice of Representatives}

We now turn to the election stage. Citizens, in each region, vote simultaneously to elect their representatives to their regional legislature. We restrict attention to a political equilibrium such that given the identity of the representative of the other region; the domestic representative is preferred 
by a majority of the domestic voters. The solution of this majority problem is given by the median voter theorem, i.e., the representative that is majority-preferred to any other representatives is the one that is most preferred by the voter with the median income, $m_{i}$, in each region. This is because the difference in welfare between citizens in a region is linear in income, hence single-peakedness holds. We therefore assume, in the following, that the elected representative in each region is of this majority-preferred type. ${ }^{10}$

The payoff of region $i$ 's median voter with income $m_{i}$, given representatives $\left(x_{i}, x_{j}\right)$ is given by

$W_{m_{i}}^{D}\left(m_{i}, x_{i}, x_{j}\right)=\left\{0,5+(0,5 a+\gamma)\left[0,5 a\left(x_{1}+x_{2}\right)+\gamma\left(x_{i}-x_{j}\right)\right]\right\} m_{i}-0,5(0,5 a+\gamma)^{2} x_{i}^{2} ; \quad i \neq j$

The optimal representative type $x_{i}$ for the median voter in region $i$ is therefore given by the solution to

$$
\frac{\partial W_{m_{i}}^{D}\left(m_{i}, x_{i}, x_{j}\right)}{\partial x_{i}}=0 \Leftrightarrow(0,5 a+\gamma)^{2}\left(m_{i}-x_{i}\right)=0
$$

which is independent of $x_{j}$. In equilibrium, we then have $x_{i}=m_{i}$ for $i \in\{1,2\}$. Thus, we have

Lemma 1 : Under a decentralized system, the median voter in each region prefers a representative of his own type. The equilibrium level of enforcement, under decentralization, is then given for $i \in\{1,2\}$ by

$$
\alpha_{i}^{D}\left(m_{i}\right)=[0,5 a+\gamma] m_{i}
$$

It is interesting to compare these levels with the first best optimal levels given in equation (5). We have

$$
\widetilde{\alpha}_{i} \gtreqless \alpha_{i}^{D}\left(m_{i}\right) \text { as } a \gtreqless 2 \gamma \text {. }
$$

Therefore when $a$ is high enough relative to $\gamma$, the diffusion externality dominates the displacement externality and there is under-deterrence (with respect to the optimal level) in the decentralized equilibrium. If, however, $\gamma$ is relatively strong, there is too much enforcement in a decentralized

\footnotetext{
${ }^{10}$ There are two possible theoretical foundations for assuming such an outcome. First, in a citizen-candidate model with citizens choosing whether or not to become candidates in the election, there exists an equilibrium in which a candidate of the majority-type is elected. Whether a unique candidate or several candidates of the majority-preferred type run for office depends upon the costs of running and upon the perquisites of office (see Osborne and Slivinsky (1997) and Besley and Coate (1997)). Second, in a Downsian model with two political parties competing for office, equilibrium involves both parties selecting the policy that is preferred by the median voter. Further, note that we could obtain results similar to those obtained in this paper if we instead used a model in which individuals in a given region all have the same income, but income vary between regions.
} 
equilibrium. This is because with strong displacement potential, each region tries to invest more than the other to export its criminals.

The decentralized equilibrium payoff of a voter with income $x$ living in region $i$ is then given by

$$
W_{i}^{D}(x)=\left\{0,5+(0,5 a+\gamma)\left[0,5 a\left(m_{1}+m_{2}\right)+\gamma\left(m_{i}-m_{j}\right)\right]\right\} x-0,5(0,5 a+\gamma)^{2} m_{i}^{2} ; \quad i \neq j .
$$

Recall that by assumption, there is a continuum of citizens of unit mass in each region and that the median of the income distribution also corresponds to its mean. Hence, the payoff of region $i$ 's median voter also represents aggregate welfare. Aggregate welfare in region $i$ is thus given by

$$
W_{i}^{D}\left(m_{i}\right)=\left[0,5+0,5(0,5 a+\gamma)^{2} m_{i}+\left(0,25 a^{2}-\gamma^{2}\right) m_{j}\right] m_{i} ; \quad i \neq j .
$$

\section{Centralization with an Elected Government}

Under centralization, the policy outcome is also determined by a two-stage policy game. In the first stage, citizens in each region elect their representative to the central legislature. In the second stage, the two representatives in the central legislature choose the level of enforcement for each region. To model this policy stage, we follow Besley and Coate (2003) and in particular, the minimum winning coalition approach. Under this view, a policy is adopted by the central legislature when a minimal number of its members support the policy. We assume that the minimum size of the coalition required to "win a vote" is $50 \%$ of the members of the central legislature. Thus, given the central legislature has two members, each representative can be thought of as a minimum winning coalition. Therefore, it is assumed that each region's representative forms the minimum winning coalition and chooses policy with a probability of $1 / 2$. In other words, enforcement levels $\left(\alpha_{1}, \alpha_{2}\right)$ are chosen by the representative of region 1 with probability $1 / 2$, and by that of region 2 with the same probability.

\section{$5.1 \quad$ Enforcement Levels}

We first determine the outcome of the policy stage. Let the types of the elected representatives in region 1 and 2 be $x_{1}$ and $x_{2}$. Since the costs of enforcement are equally shared, the optimal level of enforcement for region $i$ 's representative is obtained by maximizing

$$
W_{i}=\left(1-c_{i}\right) x_{i}-\frac{\alpha_{1}^{2}+\alpha_{2}^{2}}{4}
$$

with respect to $\alpha_{1}$ and $\alpha_{2}$. We assume that the representative of region $i$ cannot choose a negative level of enforcement for region $j$. Hence, we impose a positivity constraint $\alpha_{i} \geq 0$ for $i=\{1,2\}$. 
Let the levels of enforcement chosen by a representative of type $x_{i}$ of region $i$ be denoted by $\alpha_{1}\left(x_{i}\right)$ and $\alpha_{2}\left(x_{i}\right)$. The first-order conditions characterizing these levels of enforcement are

$$
\begin{aligned}
& {\left[\frac{1}{2} a+\gamma\right] x_{i}-\frac{1}{2} \alpha_{i}\left(x_{i}\right)=0} \\
& {\left[\frac{1}{2} a-\gamma\right] x_{i}-\frac{1}{2} \alpha_{j}\left(x_{i}\right)=0, \quad i \neq j .}
\end{aligned}
$$

Solving this system, we find

$$
\begin{aligned}
& \alpha_{i}\left(x_{i}\right)=[a+2 \gamma] x_{i} \\
& \alpha_{j}\left(x_{i}\right)= \begin{cases}{[a-2 \gamma] x_{i}, \quad i \neq j,} & \text { if } a \geq 2 \gamma \\
0, & \text { if } a<2 \gamma\end{cases}
\end{aligned}
$$

We thus have $\alpha_{i}\left(x_{i}\right)>\alpha_{j}\left(x_{i}\right)$ irrespective of the level of income of representative $x_{i}$. In addition, if the diffusion parameter $a$ is low relative to the displacement parameter $\gamma$, then the elected representative will invest in enforcement only in his/her region. If, however, the diffusion parameter is relatively high, the elected representative will optimally invest in the two regions because of the convexity of the cost of enforcement functions. We thus need to consider two cases, depending on whether or not $a$ is greater than $2 \gamma$. Abusing notation, we denote by $c_{j}\left(x_{i}\right) \equiv c_{j}\left(\alpha_{i}\left(x_{i}\right), \alpha_{j}\left(x_{i}\right)\right)$ the equilibrium number of criminals in region $j$ when representative $x_{i}$ of region $i$ chooses the levels of enforcement. Using the equilibrium levels of enforcement in equation (21), we obtain the following equilibrium number of criminals

$$
\begin{aligned}
& \text { If } a \geq 2 \gamma\left\{\begin{array}{l}
c_{i}\left(x_{i}\right)=0,5-a^{2} x_{i}-4 \gamma^{2} x_{i} \\
c_{j}\left(x_{i}\right)=0,5-a^{2} x_{i}+4 \gamma^{2} x_{i}, \quad i \neq j
\end{array}\right. \\
& \text { If } a<2 \gamma\left\{\begin{array}{l}
c_{i}\left(x_{i}\right)=0,5-0,5(a+2 \gamma)^{2} x_{i} \\
c_{j}\left(x_{i}\right)=0,5-0,5\left(a^{2}-4 \gamma^{2}\right) x_{i}, \quad i \neq j .
\end{array}\right.
\end{aligned}
$$

Observe that in both cases, we have $c_{i}\left(x_{i}\right)<c_{j}\left(x_{i}\right)$. In other words, elected representatives always spend more in enforcement in their region of origin than in the other region, and this translates into the number of criminals in their region of origin being smaller than that in the other region.

\subsection{Choice of Representatives}

We now turn to the election stage. If the representatives are of types $x_{1}$ and $x_{2}$, the policy outcome in the second stage of the game will be $\left(\alpha_{1}\left(x_{1}\right), \alpha_{2}\left(x_{1}\right)\right)$ with probability $1 / 2$, and $\left(\alpha_{1}\left(x_{2}\right), \alpha_{2}\left(x_{2}\right)\right)$ with probability $1 / 2$. In the first stage, a political equilibrium is such that given the identity of the representative of the other region, the domestic representative is preferred by a majority of the domestic voters. Because of the linearity of individual welfare in $x$, the majority rule equilibrium coincides with the decision that is optimal for the median voter. 
When the representatives in the central legislature are of type $x_{i}$ and $x_{j}$, region $i$ 's median voter $m_{i}$ has the following expected payoff function

$$
\begin{aligned}
W_{m_{i}}^{C}\left(m_{i}, x_{i}, x_{j}\right) & =\frac{1}{2}\left[\left(1-c_{i}\left(x_{i}\right)\right) m_{i}-\frac{\alpha_{i}\left(x_{i}\right)^{2}+\alpha_{j}\left(x_{i}\right)^{2}}{4}\right] \\
& +\frac{1}{2}\left[\left(1-c_{i}\left(x_{j}\right)\right) m_{i}-\frac{\alpha_{i}\left(x_{j}\right)^{2}+\alpha_{j}\left(x_{j}\right)^{2}}{4}\right] ; i \neq j .
\end{aligned}
$$

The most preferred representative of region $i$ 's median voter $m_{i}$ is given by

$$
\begin{aligned}
& \text { If } a \geq 2 \gamma: \quad \frac{\partial W_{m_{i}}^{C}\left(m_{i}, x_{i}, x_{j}\right)}{\partial x_{i}}=0 \Leftrightarrow \frac{1}{2}\left(a^{2}+4 \gamma^{2}\right)\left(m_{i}-x_{i}\right)=0, \\
& \text { If } a<2 \gamma: \quad \frac{\partial W_{m_{i}}^{C}\left(m_{i}, x_{i}, x_{j}\right)}{\partial x_{i}}=0 \Leftrightarrow \frac{1}{4}(a+2 \gamma)^{2}\left(m_{i}-x_{i}\right)=0 .
\end{aligned}
$$

In equilibrium, independently of $x_{j}$ and independently of whether $a \gtreqless 2 \gamma$, we have $x_{i}=m_{i}$, for $i \in\{1,2\}$.

Lemma 2 : Under a centralized system with a non-cooperative legislature, the median voter in each region prefers a representative of his own type. Region i's median voter has a probability $1 / 2$ of being the decision-maker for the two regions in which case the equilibrium levels of enforcement are

$$
\begin{aligned}
& \alpha_{i}^{C}\left(m_{i}\right)=[a+2 \gamma] m_{i}, \\
& \alpha_{j}^{C}\left(m_{i}\right)= \begin{cases}{[a-2 \gamma] m_{i}, \quad i \neq j} & \text { if } \quad a \geq 2 \gamma \\
0 & \text { if } \quad a<2 \gamma\end{cases}
\end{aligned}
$$

We can compare these equilibrium levels with the first best optimal levels of enforcement given in equation (5). First consider the equilibrium choice of enforcement by a representative for his/her region of origin. We have

$$
\alpha_{i}^{C}\left(m_{i}\right) \gtreqless \widetilde{\alpha}_{i} \quad \text { as } \quad \frac{m_{i}}{m_{j}} \gtreqless \frac{0,5 a-\gamma}{0,5 a+\gamma} .
$$

When $a<2 \gamma$, region $i$ 's representative will spend too much in enforcement in his/her region of origin relative to the optimal level independently of $m_{i}$ and $m_{j}$. When $a \geq 2 \gamma$, this will be also the case if region $i$ is richer than region $j$. Further, even if $a \geq 2 \gamma$ and region $i$ is poorer than region $j$ $\left(m_{i}<m_{j}\right)$, region $i$ 's representative may spend too much in enforcement in his/her region of origin, although the reverse is also possible.

Consider now the equilibrium choice of enforcement by a representative of region $i$ for region $j$. We have 


$$
\begin{aligned}
& \alpha_{j}^{C}\left(m_{i}\right) \underset{<}{<} \widetilde{\alpha}_{j} \quad \text { as } \quad \frac{m_{i}}{m_{j}} \gtreqless \frac{0,5 a+\gamma}{0,5 a-\gamma} \quad \text { if } \quad a \geq 2 \gamma, \\
& \alpha_{j}^{C}\left(m_{i}\right)<\widetilde{\alpha}_{j} \quad \text { if } \quad a<2 \gamma .
\end{aligned}
$$

Again, the comparison depends on the relative size of all parameters $m_{i}, m_{j}, a$ and $\gamma$. More precisely, when $a \geq 2 \gamma$, region $i$ 's representative is likely to choose, for region $j$, a lower level of investment than the optimal level except if he/she is significantly more wealthier than region $j$ 's representative. When $a<2 \gamma$, region $i$ 's representative does not invest in the other region whether he/she is wealthier or poorer than region $j$ 's representative and so, there is under-investment in region $j$ with respect to the optimal level. (Recall that we assumed $m_{i} / m_{j}<(\gamma+0.5 a) /(\gamma-0.5 a)$ when $a<2 \gamma$ and $m_{i}>m_{j}$, which implies that $\widetilde{\alpha}_{j}>0$ ).

We can also compare equilibrium enforcement under centralization and decentralization. The following can be observed

$$
\begin{aligned}
& \alpha_{i}^{C}\left(m_{i}\right)=2 \alpha_{i}^{D}\left(m_{i}\right), \\
& \alpha_{j}^{C}\left(m_{i}\right) \geqq \alpha_{j}^{D}\left(m_{j}\right) \quad \text { as } \quad \frac{m_{i}}{m_{j}} \geqq \frac{0,5 a+\gamma}{2(0,5 a-\gamma)} \quad \text { if } \quad a \geq 2 \gamma, \\
& \alpha_{j}^{C}\left(m_{i}\right)<\alpha_{j}^{D}\left(m_{j}\right) \quad \text { if } \quad a<2 \gamma .
\end{aligned}
$$

In words, if region $i$ 's median voter is the decision maker under centralization, he will choose a higher level of enforcement at home than under decentralization and in most cases, a lower level for the other region than that the other region would have chosen under decentralization (except if region $i$ 's representative is much more wealthier than region $j$ 's representative and $a \geq 2 \gamma$ ).

The expected level of welfare of a voter with income $x$ in region $i$ under a centralized system is then

$$
\begin{aligned}
\text { If } \quad a \geq 2 \gamma: \quad W_{i}^{C}(x)= & \frac{1}{2}\left[1+a^{2}\left(m_{1}+m_{2}\right)+4 \gamma^{2}\left(m_{i}-m_{j}\right)\right] x \\
& -\frac{1}{4}\left(a^{2}+4 \gamma^{2}\right)\left(m_{1}^{2}+m_{2}^{2}\right) ; \quad i \neq j, \\
\text { If } \quad a<2 \gamma: \quad W_{i}^{C}(x)= & \frac{1}{2}\left[1+0,5(a+2 \gamma)^{2} m_{i}+0,5\left(a^{2}-4 \gamma^{2}\right) m_{j}\right] x \\
& -\frac{1}{8}(a+2 \gamma)^{2}\left(m_{1}^{2}+m_{2}^{2}\right) ; \quad i \neq j .
\end{aligned}
$$

Finally, the expected level of welfare for region $i$ 's median voter, hence aggregate welfare in region $i$, can be computed as follows

If $\quad a \geq 2 \gamma: \quad W_{i}^{C}\left(m_{i}\right)=0,5 m_{i}+\left(0,25 a^{2}+\gamma^{2}\right)\left(m_{i}^{2}-m_{j}^{2}\right)+\left(0,5 a^{2}-2 \gamma^{2}\right) m_{1} m_{2} ; \quad i \neq j$,

If $\quad a<2 \gamma: \quad W_{i}^{C}\left(m_{i}\right)=0,5 m_{i}+0,125(a+2 \gamma)^{2}\left(m_{i}^{2}-m_{j}^{2}\right)+0,25\left(a^{2}-4 \gamma^{2}\right) m_{1} m_{2} ; \quad i \neq j$ 


\section{Constitutional Stage: Centralization or Decentralization}

Suppose now that voters in the two regions have to decide on the best manner to deal with criminality. As is understood from previous sections, the technology of crime and crime enforcement can be described by parameters $(a, \gamma)$. In practice, there are many types of crimes and associated crime enforcement, and they can be described by various combinations of the technological parameters. Suppose for now that all crime is of specific type $(a, \gamma)$. Given this, we now wish to determine which system, between centralization and decentralization, would actually be chosen by voters to fight this specific type of crime. Thus, suppose that prior to the two-stage game (choice of representatives and choice of enforcement) described and analyzed in previous sections, voters in each region can decide in an initial constitutional stage, by majority voting, whether or not the regions should agree to a centralized system. We assume that for centralization to occur, it must be supported by a majority of voters in both regions. Focusing on subgame perfect equilibria, we now analyze the initial constitutional stage of this game, when the players anticipate the outcomes of the subsequent two-stage game.

To determine the outcome of this constitutional stage, we need a measure, for each voter, of the difference in welfare under centralized and decentralized policy-making. Let $\Delta_{i}\left(x, m_{i}, m_{j}\right) \equiv$ $W_{i}^{C}\left(x, m_{i}, m_{j}\right)-W_{i}^{D}\left(x, m_{i}, m_{j}\right)$ be that measure for a voter with income $x$ in region $i$. Hence, this voter will vote for centralization (decentralization) if and only if $\Delta_{i}\left(x, m_{i}, m_{j}\right)$ is positive (negative). In addition, in what follows, we need to make a distinction between $a<2 \gamma$ and $a \geq 2 \gamma$ since this crucially affects the outcomes of the subsequent stages. Actually, this distinction parallels the difference between over-deterrence $(a<2 \gamma)$ and under-deterrence $(a \geq 2 \gamma)$ with respect to the first best levels, when decisions are decentralized (see equation (16)). We first consider the simplest case, i.e. $a<2 \gamma$.

\subsection{General Case With $a<2 \gamma$ (Low Diffusion, High Displacement)}

Recall that in this case and under centralized policy-making, the central legislature of elected representatives will invest in enforcement activities only in the region that belongs to the minimum winning coalition. There is no investment in such activities in the other region. In this case, the welfare difference between centralization and decentralization, with the use of equations (17) and (29), is given for $i=\{1,2\}$ by:

$$
\Delta_{i}\left(x, m_{1}, m_{2}\right)=-0,125(a+2 \gamma)^{2} m_{j}^{2}, \quad i \neq j .
$$

We then have the following Proposition. 
Proposition 1 : When $a<2 \gamma$, a majority of voters in both regions vote for decentralization irrespective of the asymmetry in median wealth between the two regions.

In this situation, i.e. for any $a<2 \gamma$, there is always unanimity for decentralization. The reason is that under a centralized system, each region has a probability $1 / 2$ of getting a disproportionate share of the criminals since with probability $1 / 2$ the representative of the other region is chosen as the agenda-setter, in which case, he will only invest in enforcement at home (see Lemma 2).

\subsection{General Case With $a \geq 2 \gamma$ (High Diffusion, Low Displacement)}

In this case and using equations (17) and (29), the welfare difference between centralization and decentralization is given for $i=\{1,2\}$ by:

$$
\begin{aligned}
\Delta_{i}\left(x, m_{1}, m_{2}\right)= & (0,5 a-\gamma)\left[0,5 a\left(m_{1}+m_{2}\right)-\gamma\left(m_{i}-m_{j}\right)\right] x \\
& -\left(0,25 a^{2}+\gamma^{2}\right) m_{j}^{2}-0,5(0,5 a-\gamma)^{2} m_{i}^{2}, \quad i \neq j
\end{aligned}
$$

Observe that these expressions are monotonically increasing in $x$. Because the coefficient of $x$ differs in the two expressions, there must be a $\widetilde{x}_{i}$ corresponding to the income type of the voter who is indifferent between centralization and decentralization in region $i$. Thus, $\widetilde{x}_{i}$ is such that $\Delta_{i}\left(x, m_{1}, m_{2}\right)=0$. Clearly, all voters $x$ in region $i$ with $x \geq \widetilde{x}_{i}$ prefer centralization to decentralization. Because single-peakedness holds, it must then be that a majority of voters in region $i$ prefer centralization if and only if $\widetilde{x}_{i} \leq m_{i}$. We then have the following Lemma

Lemma 3 : Under majority voting, centralization will occur in equilibrium if and only if $\widetilde{x}_{i} \leq m_{i}$ for $i=\{1,2\}$ with

$$
\widetilde{x}_{i}=\frac{(0,5 a-\gamma)^{2} m_{i}^{2}+\left(0,5 a^{2}+2 \gamma^{2}\right) m_{j}^{2}}{(a-2 \gamma)\left[0,5 a\left(m_{1}+m_{2}\right)-\gamma\left(m_{i}-m_{j}\right)\right]} ; \quad i \neq j
$$

Before analyzing the outcome of the constitutional stage for any $(a, \gamma)$, we first consider particular cases to better understand the effects at work.

\subsubsection{Case With No Displacement $(\gamma=0)$ and Heterogenous Regions}

Consider the case in which $a>0$ and $\gamma=0$ so that $a>2 \gamma$ obviously holds. Assuming $m_{1} \neq m_{2}$ and using (33), we have

$$
\widetilde{x}_{i}=\frac{m_{i}^{2}+2 m_{j}^{2}}{2\left(m_{i}+m_{j}\right)} ; \quad i \neq j
$$


In region $i$, all individuals with $x \geq \widetilde{x}_{i}$ vote for centralization while individuals with $x<\widetilde{x}_{i}$ vote for decentralization. Observe also that $\widetilde{x}_{i}$ depends only on $m_{1}$ and $m_{2}$ (and then does not depend on a). We then have the following Proposition.

Proposition 2 : Assume no displacement occurs, i.e. $\gamma=0$. Then, for any a $>0$, centralization will occur in equilibrium if and only if the median income of the richer region is not larger than $[1+\sqrt{3}] / 2$ times the median income of the poorer region.

According to Lemma 3, centralization will occur in equilibrium if and only if both $\widetilde{x}_{i} \leq m_{i}$ for $i=\{1,2\}$. Using (34), this inequality reduces to $\left(m_{j}-m_{i}\right)\left(m_{i}+m_{j}\right) \leq m_{j}\left(2 m_{i}-m_{j}\right)$. Assume region 2 is the richer region, i.e. $m_{2}>m_{1}$. In this case $\widetilde{x}_{2} \leq m_{2}$ is obviously verified. To determine under which condition the inequality $\widetilde{x}_{1} \leq m_{1}$ is satisfied let $m_{2}=k m_{1}$ with $k>1$. With this notation, the above inequality reduces to $2 k^{2}-2 k-1 \leq 0$. It is immediately checked that this inequality is indeed negative for any $k>1$ if and only $k \leq[1+\sqrt{3}] / 2$.

Put another way, a majority a voters in both regions will vote for centralization if and only if the difference in median wealth between the two regions is relatively small. When criminals cannot move from one region to the other, there is only one inter-regional (positive) externality stemming from local investment in deterrence activities. Policy centralization allows to internalize the diffusion externality but each median voter has only a probability $1 / 2$ of being the policy-maker. Since the cost of law enforcement is shared equally between the two regions, a majority of voters vote for centralization in the two regions if and only if the asymmetry in wealth between the two regions is not too strong relative to the benefits of internalizing the diffusion externality.

If however, the difference in median wealth between the two regions is large, decentralization will prevail. Suppose, for example, that in region 1, the distribution of wealth is skewed with most individuals having little or almost no wealth (i.e. $m_{1}$ is close to 0 ). In this case, we have

$$
\begin{aligned}
\lim _{m_{1} \rightarrow 0} \widetilde{x}_{1} & =m_{2}, \\
\lim _{m_{1} \rightarrow 0} \widetilde{x}_{2} & =\frac{m_{2}}{2} .
\end{aligned}
$$

In this case, a majority of voters in region 2 will vote for centralization while a majority of voters in region 1 vote for decentralization (since $m_{1} \lll m_{2}$ ). So in equilibrium, centralization will not take place. This is because under decentralization, the level of enforcement in region 1 is almost equal to 0 (since most individuals are already very poor), while under centralized policy-making, this region has a probability $1 / 2$ of not being the agenda-setter in which case it will have to pay $1 / 2$ of the level of enforcement that is preferred by the median voter of the other region (who is actually much more wealthier). Voters in region 1 are afraid of this possibility and they therefore vote against centralization. 


\subsubsection{Case With Displacement $\gamma \neq 0$ and Homogenous Regions $\left(m_{1}=m_{2}\right)$}

We now examine the case in which $\gamma \neq 0$ (but $a \geq 2 \gamma$ ) and we impose homogenous regions so that $m_{1}=m_{2}=m$. Using (33), $\widetilde{x}$, the income of the voter who is indifferent in both regions between centralized and decentralized policy-making, is given by

$$
\widetilde{x}=\frac{\left[3 a^{2}+12 \gamma^{2}-4 a \gamma\right] m}{4 a(a-2 \gamma)} .
$$

The derivative of $\widetilde{x}$ with respect to $a$ is given by

$$
\frac{\partial \widetilde{x}}{\partial a}=\frac{\left[12 \gamma^{2}(\gamma-a)-a^{2}\right] m}{2[a(a-2 \gamma)]^{2}}<0 .
$$

Therefore, a higher $a$ (i.e. a higher diffusion effect of law enforcement) translates into a voter who is indifferent between centralized and decentralized policy-making with a lower income and, therefore, into a higher proportion of voters who prefer a centralized system (provided that $a \geq 2 \gamma$ ). When the parameter reflecting diffusion goes to infinity, we have $\widetilde{x}=(3 / 4) m$. In that case, all voters with income higher than $3 / 4$ of the median income prefer a centralized system and therefore a majority of individuals in both regions will vote for centralized policy-making. On the other extreme, when $a=2 \gamma, \widetilde{x}$ goes to infinity and all voters in both regions prefer a decentralized system.

Similarly, the derivative of $\widetilde{x}$ with respect to $\gamma$ is given by

$$
\frac{\partial \widetilde{x}}{\partial \gamma}=\frac{\left[12 \gamma(a-\gamma)+a^{2}\right] m}{2 a(a-2 \gamma)^{2}}>0
$$

Therefore, a higher $\gamma$ (i.e. more potential for displacement) translates into a voter who is indifferent between centralized and decentralized policy-making with a higher income and, therefore, into a higher proportion of voters who prefer a decentralized system (provided that $\gamma \in[0, a / 2]$ ). When the displacement parameter goes to zero, we have again $\widetilde{x}=(3 / 4) m$ and so all voters with income higher than $3 / 4$ of the median income prefer a centralized system and therefore a majority of individuals in both regions will vote for centralized policy-making. At the other extreme, when $\gamma=a / 2, \widetilde{x}$ goes to infinity and all voters in both regions prefer a decentralized system.

To summarize, the lower the spatial displacement effect and the higher the diffusion effect of law enforcement, the higher the proportion of voters who will vote for centralization. Following Lemma 3 , centralization will occur in equilibrium if and only if $\widetilde{x} \leq m$ with $\widetilde{x}$ given by (36). This inequality reduces to $12 \gamma^{2}+4 a \gamma-a^{2} \leq 0$. We can thus establish the following Proposition.

Proposition 3 : Suppose that $a>2 \gamma$ and that the two median voters are equally wealthy, i.e. $m_{1}=m_{2}=m$, then a majority of voters in both regions will vote for centralization (respectively 
decentralization) if and only if $a \geq \widetilde{a}(\gamma)$ (respectively $a<\widetilde{a}(\gamma))$ with $\widetilde{a}(\gamma)=6 \gamma$.

From a political economy perspective, decentralization may be preferred by a majority of voters in both regions even though the two regions are perfectly identical. This is because, under centralization, the minimum winning coalition approach of policy-making gives rise to a political risk, as each region is not certain that its representative will belong to the winning coalition. Because the costs of investments in deterrence activities are equally shared, the political risk is reflected in spending that is skewed towards regions whose representatives are inside the winning coalition, to the detriment of the other regions. Furthermore, as shown by (21), the larger the displacement effect and the lower the diffusion effect of law enforcement, the greater the distortion in spending across the two regions. Put another way, the diffusion effect of law enforcement, represented by $a$, must be sufficiently large relative to the diffusion effect, represented by $\gamma$, for centralization to occur. If not, both regions vote for decentralization. Note that the case in which $\gamma$ is large is precisely that in which the externality due to the mobility of criminals is large and in which a well-functioning central government would prove useful. But from a political economy perspective, higher mobility of criminal leads those in the minimum winning coalition to distort public spending in deterrence activities across the two regions to a larger extent in order to reduce the number of criminals operating in their jurisdictions.

\subsubsection{Different Types of Crimes}

We now turn to the most general case when $a \geq 2 \gamma>0$. According to Lemma 3, centralization will occur in equilibrium if and only if a majority of voters in both regions vote for centralization, i.e. if and only if $\widetilde{x}_{i} \leq m_{i}$ for $i=\{1,2\}$ with $\widetilde{x}_{i}$ given by (33). The two inequalities reduce to $a \geq \widetilde{a}_{1}\left(\gamma, m_{1}, m_{2}\right)$ and $a \geq \widetilde{a}_{2}\left(\gamma, m_{1}, m_{2}\right)$ with $\widetilde{a}_{1}\left(\gamma, m_{1}, m_{2}\right)$ and $\widetilde{a}_{2}\left(\gamma, m_{1}, m_{2}\right)$ given by

$$
\begin{aligned}
& \widetilde{a}_{1}\left(\gamma, m_{1}, m_{2}\right)=\frac{\gamma\left[2 m_{1}^{2}+5,66 m_{2} \sqrt{m_{1}^{2}-0,5 m_{2}^{2}}\right]}{m_{1}^{2}+2 m_{1} m_{2}-2 m_{2}^{2}}, \\
& \widetilde{a}_{2}\left(\gamma, m_{1}, m_{2}\right)=\frac{\gamma\left[2 m_{2}^{2}+5,66 m_{1} \sqrt{m_{2}^{2}-0,5 m_{1}^{2}}\right]}{m_{2}^{2}+2 m_{1} m_{2}-2 m_{1}^{2}} .
\end{aligned}
$$

Suppose now that region 1 is poorer than region 2, i.e. $m_{2}>m_{1}$. If we denote $m_{2}=k m_{1}$ with $k>1$, the above expressions can be written as follows

$$
\begin{aligned}
& \tilde{a}_{1}(\gamma, k)=\frac{\gamma\left[2+5,66 k \sqrt{1-0,5 k^{2}}\right]}{1+2 k-2 k^{2}}, \\
& \tilde{a}_{2}(\gamma, k)=\frac{\gamma\left[2 k^{2}+5,66 \sqrt{k^{2}-0,5}\right]}{k^{2}+2 k-2} .
\end{aligned}
$$


Observe first that both expressions are linear with respect to $\gamma$. Second, $\widetilde{a}_{2}(\gamma, k)$ is strictly positive for any $k>1$ and $\widetilde{a}_{1}(\gamma, k)$ is also strictly positive if and only if $1+2 k-2 k^{2}>0$. If however, $1+2 k-2 k^{2}<0$, then $\widetilde{a}_{1}(\gamma, k)<0$ and $\widetilde{x}_{1}>m_{1}$ for any couple $(a, \gamma)$. In this case, a majority of voters in region 1 vote for decentralization irrespective of the technology of crime enforcement. Therefore, there exists a threshold value of the parameter reflecting the diffusion externality above (below) which centralization (decentralization) is preferred by a majority of voters in region 1 if and only if $1+2 k-2 k^{2}>0$ or $k<[1+\sqrt{3}] / 2 .^{11}$

Furthermore, calculating the derivative of $\widetilde{a}_{1}(\gamma, k)$ with respect to $k$ yields

$$
\frac{\partial \widetilde{a}_{1}(\gamma, k)}{\partial k}=\frac{\gamma\left[4(2 k-1)+5.66\left(1-0.5 k^{2}\right)^{-1 / 2}\left(1+k^{2}-k^{3}\right)\right]}{\left[1+2 k-2 k^{2}\right]^{2}} .
$$

Since $1+k^{2}-k^{3}>0$ for any $k<[1+\sqrt{3}] / 2$, this derivative is unambiguously positive. Calculating the derivative of $\widetilde{a}_{2}(\gamma, k)$ with respect to $k$ yields

$$
\frac{\partial \widetilde{a}_{2}(\gamma, k)}{\partial k}=-\frac{\gamma\left[4 k(2-k)+5.66\left(k^{2}-0.5\right)^{-1 / 2}\left(k^{3}+k-1\right)\right]}{\left[k^{2}+2 k-2\right]^{2}} .
$$

This derivative is unambiguously negative for any $k<[1+\sqrt{3}] / 2$. Since $\widetilde{a}_{1}(\gamma, k)=\widetilde{a}_{2}(\gamma, k)$ when $k=1$, we can conclude that $\widetilde{a}_{1}(\gamma, k) \geq \widetilde{a}_{2}(\gamma, k)$ for any $k \in[1 ;[1+\sqrt{3}] / 2[$. Then, a majority of voters in both regions will vote for centralization if and only if $a>\widetilde{a}_{1}(\gamma, k) \geq \widetilde{a}_{2}(\gamma, k)$. The analysis above is summarized as Proposition 4.

Proposition $4:$ Suppose that $a>2 \gamma>0$ and that $m_{2}=k m_{1}$ with $k>1$, then

(i) If the median wealth asymmetry is relatively strong, i.e. if $k>[1+\sqrt{3}] / 2$, a majority of voters in the poorer region vote for decentralization irrespective of the levels of the diffusion effect and displacement effect of law enforcement given by $(a, \gamma)$ and so, decentralization occurs in equilibrium.

(ii) If the median wealth asymmetry is not too strong, i.e. if $k<[1+\sqrt{3}] / 2$, then centralization occurs in equilibrium if and only if a majority of voters in the poorer region vote for centralization, i.e. if and only if $a \geq \widetilde{a}_{1}(\gamma, k)$ with $\widetilde{a}_{1}(\gamma, k)$ given by (40), otherwise decentralization occurs. The threshold value of the diffusion effect $\widetilde{a}_{1}(\gamma, k)$ is increasing both in $\gamma$ and in $k$ and so, the greater the displacement effect of law enforcement (the greater $\gamma$ ) or the greater the median wealth asymmetry (the greater $k$ ), the less likely centralization will occur in equilibrium.

Observe that the critical value of the median wealth asymmetry above which decentralization is

\footnotetext{
${ }^{11}$ The term in $\sqrt{ }$ in the numerator of $\widetilde{a}_{1}(\gamma, k)$ must also be positive in order to have a real positive number. This is the case for any $k<[1+\sqrt{3}] / 2<\sqrt{2}$.
} 
always preferred by a majority of voters in the poorer region is identical to that obtained when there is no displacement effect, i.e. when $\gamma=0$ (see Proposition 2). However, in contrast with the case of no displacement, a value of $k$ below this critical level is not sufficient to yield centralization of law enforcement as an equilibrium outcome when $\gamma>0$. Indeed, with $k<[1+\sqrt{3}] / 2$, centralization is preferred by a majority of voters in the poorer region, and in turn in the richer region, if and only if the diffusion effect relative to the displacement effect of law enforcement is sufficiently large, i.e. if and only if $a \geq \widetilde{a}_{1}(\gamma, k)$. If, however, $\widetilde{a}_{2}(\gamma, k) \leq a \leq \widetilde{a}_{1}(\gamma, k)$ or $a \leq \widetilde{a}_{2}(\gamma, k)$, a majority of voters in the poorer region or in both regions prefer decentralization to centralization so that, in equilibrium, decentralization occurs.

To better understand Proposition 4, note that the decision-maker, under centralization, chooses a level of enforcement in deterrence activities for both regions that is increasing in $a$. However, the decision-maker chooses a level of enforcement that is skewed towards his/her own region and, in addition, that is increasing in $\gamma$ at home and decreasing in $\gamma$ abroad (see equation (25)). Hence, the greater $a$ relative to $\gamma$, the less detrimental is the centralized system for the region whose representative is not the decision-maker. If $a$ is sufficiently large, a majority of voters in both regions then vote for centralization so as to internalize the positive externality of law enforcement. If, however, $a$ is not sufficiently large relative to $\gamma$, then one region or both prefer decentralization since a relative high mobility of criminals exacerbates the selfishness of the minimum winning coalition.

Furthermore, the poorer region is more disadvantaged than the richer region when its representative is outside the winning coalition. The reason is that the cost of law enforcement is equally shared between the two regions. Therefore, individuals in the poorer region are less likely to vote for centralization than those in the richer region. Actually, the greater the median wealth asymmetry is, the stronger the opposition at the constitutional stage between the individuals of the two regions and the less likely centralization will occur.

Assuming that $k$ is small enough to satisfy the condition given in part (ii) of Proposition 4, we can summarize, for various combinations of $(a, \gamma)$, the choice of each region between centralization and decentralization with the help of Figure 1.

\section{— FIGURE 1 HERE —}

In Figure 1 , because $m_{2}>m_{1}$, the locus $\widetilde{a}_{1}(\gamma, k)$ lies above the locus $\widetilde{a}_{2}(\gamma, k)$, which itself lies above the locus $a=2 \gamma$. The set of parameters $(a, \gamma)$ for which centralization is preferred is larger for region 2 than for region 1. As centralization occurs only if both regions agree, it follows that centralization of enforcement will only be accepted at the constitutional stage for crimes with $(a, \gamma)$ that belong to the region above the $\widetilde{a}_{1}(\gamma, k)$ locus. As explained above, for values of $a$ that are large relative 
to $\gamma$, centralization is preferred by a majority of voters in both regions while the reverse holds for values of $a$ that are low relative to $\gamma$. For intermediate values of $a$ (relative to $\gamma$ ), centralization is preferred by a majority of voters in the region 2 , but decentralization is preferred by a majority of voters in region 1. In this last case, decentralization is the equilibrium. Thus, our prediction is that at the constitutional stage, centralization of enforcement will occur only for crimes which entail a relatively high level of diffusion and a relatively low level of displacement. ${ }^{12}$

\section{Discussion}

In the above analysis, we have assumed that under centralization the costs of public spending in law enforcement are shared equally among the two regions. Consider instead the case in which the central legislature can choose both a pair of investment levels in deterrence activities $\left(\alpha_{1}, \alpha_{2}\right)$ and a pair of region-specific taxes $\left(\tau_{1}, \tau_{2}\right)$. In that situation, the region $i^{\prime}$ s representative holding power will set a tax on the other region equal to its income (net of robbery) i.e. $\tau_{j}=\left(1-c_{j}\right) m_{j}$. The winning coalition by extracting all wealth of the other district then chooses the optimal levels of investment in deterrence activities as described in section $3 .{ }^{13}$ But the region whose representative is outside the coalition ends up with zero private consumption. The political risk of being outside the coalition is then disproportionate relative to the expected benefits of centralization and thereby both regions always prefer decentralization to centralization.

Given the uniform taxation assumption, we may also investigate the implications of uniform spending allocation i.e. $\alpha_{1}=\alpha_{2}$. In that situation, region $i^{\prime}$ s representative holding power cannot discriminate across regions and consequently it eliminates completely the displacement effect of law enforcement. The analysis with uniform spending allocation is then identical to that described in section 6.2.1 with $\gamma=0$. In such circumstances and according to Proposition 2, centralization will occur in equilibrium if and only if median wealth asymmetry between the two regions is not too strong. Obviously, if the two regions are equally wealthy i.e. $m_{1}=m_{2}$ then centralization is always preferred by a majority of voters in the two regions. Indeed, uniform taxation, uniform spending allocation and identical wealth eliminate the misallocation of resources across jurisdictions and thereby the political risk of being outside the coalition.

Further, our assumption that under centralization, the costs of investment in deterrence activities are equally shared among regions is justified on empirical grounds since most centralized systems

\footnotetext{
${ }^{12}$ As was discussed in our specific example of the Introduction, diffusion is more likely when criminals are not wellinformed regarding the enforcement activities of the police, while displacement is more likely when they are perfectly informed. Thus, in this example, centralization should take place when criminals do not have good information regarding the enforcement activities of the police.

${ }^{13}$ In this case, under centralization, region $i$ 's representative will maximize $W_{i}=\left(1-c_{i}\right) m_{i}-\tau_{i}$ subject to $\alpha_{1}^{2} / 2+\alpha_{2}^{2} / 2 \leq \tau_{1}+\tau_{2}$ and to $\left(1-c_{j}\right) m_{j} \geq \tau_{j}$ for $j \neq i$. Constraints are binding and hence region $i$ 's representative will choose $\alpha_{1}$ and $\alpha_{2}$ so as to maximize $W_{i}=\left(1-c_{i}\right) m_{i}+\left(1-c_{j}\right) m_{j}-\left[\alpha_{1}^{2} / 2+\alpha_{2}^{2} / 2\right]$ which corresponds to the maximization program of a benevolent central government.
} 
of government operate (roughly) according to such rules. In fact, equal cost sharing is very often a constitutionally imposed arrangement. For example in the USA, the tax code describing the rules of federal tax collection cannot discriminate across States (e.g., see Rubinchik-Pessach (2002)). In most European countries, uniform tax rules are also at the core of budgeting institutions (e.g., see Von Hagen (1992)).

Also, typically, spending by central governments is not uniform across regions in per capita terms. Experience shows that spending is rather allocated using formulae that depends not only on population, but also on income per-capita and on several other factors (e.g., see Boadway and Wildasin (1984) and Costello (1993)).

A limitation of our analysis is that we considered only two jurisdictions. Consequently we assumed that, under centralization with a non-cooperative legislature, each of the two representatives is chosen as agenda-setter with probability $1 / 2$ and then chooses the level of law enforcement in both jurisdictions to maximize his own utility only. It would be both interesting and natural to extend the present analysis by considering that the economy is divided into many jurisdictions instead of only two. We could thus put less restrictions on the behaviour of the legislature. For example, in the simplest version of the Baron and Ferejohn $(1987,1989)$ model of legislative bargaining with $n$ districts, each representative is chosen with probability $1 / n$ to make a proposal. If a simple majority approves the proposal then it is implemented, otherwise the statu quo prevails. Since the minimum coalition is composed of legislators whose support is cheapest to obtain, this creates an incentive for strategic voting for delegates (see, for example, Chari et al. (1997)). As the distortion due to strategic delegation can exacerbate the problem of uncertainty concerning the identity of the minimum winning coalition, we conjecture that introducing more jurisdictions into our model would reinforce the likelihood of decentralization of law enforcement.

An alternative formalization of the legislative behaviour would be to introduce some form of cooperation among representatives. Indeed, several empirical studies of the US Congress find that legislatures seek unanimity rather than majority when deciding on region-specific public goods financed though general taxation. The standard explanation is that ex ante legislators enter into an implicit cooperative agreement to provide all projects - a phenomenon referred as universalism rather than just a majority in order to deal with the problem of uncertainty over the composition of winning coalitions (see Weingast (1979) and Shepsle and Weingast (1981)). However, this legislative process has also a drawback. The budgetary externality due to common financing coupled with universalistic decision-making in the legislature creates a common resource pool problem leading to an excessive provision of locally beneficial public goods (see for example DelRossi and Inman (1999)). ${ }^{14}$ In a word, removing one distortion (i.e. the uncertainty problem) may exacerbate another

\footnotetext{
${ }^{14}$ Actually, Besley and Coate (2003) in their two-region model show that if the two legislators cooperate in the
} 
distortion (i.e. the budgetary externality). It suggests that a more complete formal analysis of the legislative process with multiple jurisdictions could be a fruitful extension and could reveal additional interesting results.

Finally, the results in this paper have been derived from a simple and specific model. Firstly, we assumed that utility is linear in income implying that voters are risk-neutral. However, our qualitative results regarding voting over the (de)centralization issue should not depend crucially on this assumption although risk-aversion would lead to different equilibrium levels of law enforcement under both centralization and decentralization. Secondly, both the specification of the cost function of law enforcement and that of the function describing the number of active criminals in each region are key conditions to deriving explicit solutions for equilibrium policy choices. Again, our purpose was to make the model as easy to use as possible in order to make the logic behind our argument sufficiently clear to convince the reader of its validity in a more general (but less tractable) setting.

\section{Concluding Remarks}

A feature of crime enforcement (in particular for property crime) is that it is typically decentralized. This is despite the fact that there are interjurisdictional externalities which would justify the centralization of crime enforcement if governments were benevolent. However, if decisions are made by a legislature of locally elected representatives, as is typically the case in centralized systems, centralization has also a drawback. This is because the minimum wining coalition of representatives may distort policies in its favor and against the members outside the majority. Hence, when voting over the (de)centralization issue, voters in each region trade-off the economic benefits of internalizing externalities and the political costs of being outside the majority of the legislature with positive probability. The political choice of centralized and decentralized law enforcement crucially depends on the extent of the externalities. For example, if the negative - spatial displacement externality is sufficiently large relative to the positive - diffusion of benefits - externality, a majority of voters in both regions vote for decentralization irrespective of the respective wealths of the two regions. Centralization, however, may occur in equilibrium only if both the parameter reflecting the displacement effect and the asymmetry in median wealth between the two regions are sufficiently low.

Note that there are crimes for which geography and location play a very minor role. For example, criminals engaged in currency counterfeiting can operate from any region of a given country and

central legislature so as to maximize their joint surplus, then each district's median voter strategically delegates policy-making to a representative with stronger concerns for the local public goods. The explanation is that the strategic choice of a liberal representative is a commitment device to extract more of the common fiscal resources at the central level. However such strategies are self-defeating and this results in too much spending. In fact, strategic delegation at the election stage may nullify any element of cooperativeness within the legislature (see Cheikbossian (2000)). 
earn a living of it. In a sense, it does not matter whether such criminals operate from one region or the other, but what does matter is whether they operate or not. Thus, currency counterfeiting is a crime for which displacement is negligible while diffusion is strictly positive. It is then interesting to note that in most countries, law enforcement against currency counterfeiting is centralized, as predicted by our model. On the other hand, there are crimes for which geography and location are of crucial importance. For example, it is well documented that the victims of burglary (break and entry) are not randomly distributed in space, but are rather clustered in areas with very specific characteristics (e.g. neighborhood average income or racial mix) which can be identified on a map. ${ }^{15}$ While the fact that geography matters does not mean that displacement occurs, it remains that for such crimes, displacement is a realistic possibility. Hence, we simply note that law enforcement for burglary is typically decentralized, and this roughly conforms with the predictions of our model since for such crimes, displacement is a possibility. Of course, it would be nice to verify the claims made in this paper in a full-fledged empirical analysis. We may undertake such work in the future.

While this paper provides a possible rationale for the observed fact that law enforcement is often decentralized, the analysis is very much a first step in understanding the question. A limitation of our analysis is that we have restricted our analysis to the extreme cases where law enforcement is either fully centralized or fully decentralized. In reality, both centralized and decentralized governments invests in law enforcement, even though more investments in deterrence activities is undertaken at the local level than at the central level. Another limitation of our analysis is that we have assumed that there is a political failure at the central level but not at the local level. However, in general, the process of decision-making at the local level is also subject to political conflicts between several elected local representatives. These considerations will also have to be taken into account in our future research.

\footnotetext{
${ }^{15}$ See Bowers et al. (2004) and the references therein. Crime maps are nowadays easily found on the web. For example, see the Dallas crime map (maps.dallascityhall.com) or that of Philadelphia (cml.upenn.edu/crimebase/cbsMapRequest.asp).
} 


\section{References}

Acemoglu, D. (1995), "Reward Structure and the Allocation of Talent," European Economic Review 39, $17-33$.

A. Alesina, I. Angeloni, F. Etro, (2005), "International unions", American Economic Review 95, $602-615$.

Alesina, A., and E. Spolaore, (1997), "On the Number and Size of Nations", Quarterly Journal of Economics 112, 1027-1056.

Baron, D., and J. Ferejohn, (1987), "Bargaining and Agenda Formation in Legislatures," American Economic Review 77, 303-309.

Baron, D, and J. Ferejohn, (1989), "Bargaining in Legislatures," American Political Science Review 83, 1181-1206.

Besley, T., and S. Coate (1997), "An Economic Model of Representative Democracy", Quarterly Journal of Economics 112, 85-114.

Besley, T., and S. Coate (2003), "Centralized versus Decentralized Provision of Local Public Goods: A Political Economy Approach", Journal of Public Economics 87, 2611-2637

Boadway, R. and D. Wildasin (1984), Public Sector Economics, Toronto: Little, Brown and Co.

Bowers, K.J., and S.D. Johnson (2003), "Measuring the Geographical Displacement and Diffusion of Benefit Effects of Crime Prevention Activity", Journal of Quantitative Criminology 19, 275-301.

Bowers, K.J., S.D. Johnson, and K. Pease (2004), "Prospective Hot-Spotting: The Future of Crime Mapping?", British Journal of Criminology 44, 641-658.

Chari, V.V., Jones, L., and R. Marimon, (1997), "The Economics of Split-Ticket Voting in Representative Democracies," American Economic Review 87, 957-976.

Cheikbossian, G., (2000), "Federalism, Distributive Politics and Representative Democracy", Economics of Governance 1, 105-122.

Costello, D. (1993), "Intergovernmental Grants: What Role for the European Community?", European Economy, no. 5.

DelRossi, A.F. and R.P. Inman, (1999), "Changing the Price of Pork: The Impact of Local Cost Sharing on Legislators Demands for Distributive Public Goods, Journal of Public Economics 71, $247-273$. 
Ellingsen, T., (1998), "Externalities vs Internalities: A Model of Political Integration," Journal of Public Economics 68, 251-68.

Ferejohn, J., F. Morris, and R. McKelvey (1987), "Sophisticated Voting and Agenda Independence in the Distributive Politics Setting", American Journal of Political Science 31, 167-193.

Glaeser, E.L., B. Sacerdote, and J.A. Scheinkman (1996), "Crime and Social Interactions," Quarterly Journal of Economics 11, 507-548.

Hotte, L., and T. Van Ypersele (2008), "Individual protection against property crime: decomposing the effects of protection observability", Canadian Journal of Economics 41, 537-563

Jacob, B., L. Lefgren, and E. Moretti (2004), "The Dynamics of Criminal Behavior: Evidence from Weather Shocks", NBER Working Paper 10739.

Kling, J.R., J. Ludwig, and L.F. Katz (2005), "Neighborhood Effects on Crime for Female and Male Youth: Evidence from a Randomized Housing Voucher Experiment", Quarterly Journal of Economics 120, 87-130.

Lockwood, B. (2002), "Distributive Politics and the Benefits of Decentralization", Review of Economic Studies 69, 313-338.

Marceau, N. (1997), "Competition in Crime Deterrence", Canadian Journal of Economics 30, 844854.

Marceau, N., and S. Mongrain (2007), "Competition in Law Enforcement and Capital Allocation", mimeo, Université du Québec à Montréal.

Newlon, E. (2001), "Spillover Crime and Jurisdictional Expenditure on Law Enforcement: a Municipal Level Analysis", mimeo, University of Kentucky.

Oates, W.E. (1972), Fiscal Federalism, New York: Harcourt Bruce Jovanovich.

Osborne, M., and A. Slivinski (1996), "A Model of Political Competition with Citizen-Candidates", Quarterly Journal of Economics 111, 65-96.

M. Redoano, K.A. Scharf, (2004), "The political economy of policy centralization: Direct versus representative democracy," Journal of Public Economics 88, 799-817.

Rubinchik-Pessach, A., (2002), "Why Are Some Taxes More Equal Than Others", Working Paper. Sah, R. (1991), "Social Osmosis and Patterns of Crime," Journal of Political Economy 99, 12721295.

Shavell, S. (1991), "Individual Precautions to Prevent Theft: Private Versus Socially Optimal Behavior", International Review of Law and Economics 11, 123-132. 
Shepsle, K. and B. Weingast, (1981), "Political Preferences for the Pork Barrel," American Journal of Political Science 25, 96-111.

Statistics Canada (2006), "Police Resources in Canada, 2006", by Julie Reitano, Minister of Industry, Catalogue No 85-225-XIF, November.

Teichman, D. (2005), "The Market for Criminal Justice: Federalism, Crime Control and Jurisdictional Competition", Michigan Law Review 103, 1831-1876.

U.S. Department of Justice (2006), "Justice Expenditure and Employment in the United States, 2003", Bureau of Justice Statistics Bulletin, Office of Justice Programs, NCJ 212260, April.

Von Hagen, J. (1992), "Budgeting procedures and fiscal performance in the European Communities", Commission of the European Communities, DG II Economic Papers 96.

Weingast, B., (1979), "A Rational Choice Perspective on Congressional Norms," American Journal of Political Science 23, 245-262.

Weisburd, D., L.A. Wyckoff, J. Ready, J.E. Eck, J.C. Hinkle, and F. Gajewski (2006), "Does Crime Just Move Around the Corner? A Controlled Study of Spatial Displacement and Diffusion of Crime Control Benefits", Criminology 44, 549-592. 
Table 1:

Police Protection Expenditure and Employment by Level of Government, Canada

\begin{tabular}{|l|c|c|c|c|}
\hline & Local government & Provincial Government & Federal government & Total \\
\hline $\begin{array}{l}\text { Expenditure, 2005 } \\
\text { [millions of CAN \$] }\end{array}$ & $\begin{array}{c}5298 \\
(57.0 \%)\end{array}$ & $\begin{array}{c}2092 \\
(22.6 \%)\end{array}$ & $\begin{array}{c}1891 \\
(20.4 \%)\end{array}$ & $\begin{array}{c}9282 \\
(100 \%)\end{array}$ \\
\hline Employment, 2006 & $\begin{array}{c}36739 \\
(58.8 \%)\end{array}$ & $\begin{array}{c}9336 \\
(14.9 \%)\end{array}$ & $\begin{array}{c}16383 \\
(26.2 \%)\end{array}$ & $\begin{array}{c}62458 \\
(100 \%)\end{array}$ \\
\hline
\end{tabular}

Source: Statistics Canada (2006), "Police Resources in Canada, 2006", by Julie Reitano, Minister of Industry, Catalogue No 85-225-XIF, November.

Table 2:

Police Protection Expenditure and Employment by Level of Government, USA

\begin{tabular}{|l|c|c|c|c|}
\hline & Local government & State Government & Federal government & Total \\
\hline $\begin{array}{l}\text { Expenditure, 2003 } \\
\text { [millions of US \$] }\end{array}$ & $\begin{array}{c}57503 \\
(64.6 \%)\end{array}$ & $\begin{array}{c}11144 \\
(12.5 \%)\end{array}$ & $\begin{array}{c}20422 \\
(22.9 \%)\end{array}$ & $\begin{array}{c}89069 \\
(100 \%)\end{array}$ \\
\hline Employment, 2003 & $\begin{array}{c}856396 \\
(76.5 \%)\end{array}$ & $\begin{array}{c}105933 \\
(9.5 \%)\end{array}$ & $\begin{array}{c}156607 \\
(14.0 \%)\end{array}$ & $\begin{array}{c}1118936 \\
(100 \%)\end{array}$ \\
\hline
\end{tabular}

Source: U.S. Department of Justice (2006), "Justice Expenditure and Employment in the United States, 2003", Bureau of Justice Statistics Bulletin, Office of Justice Programs, NCJ 212260, April. 
Figure 1: The choice between centralization (C) and decentralization (D)

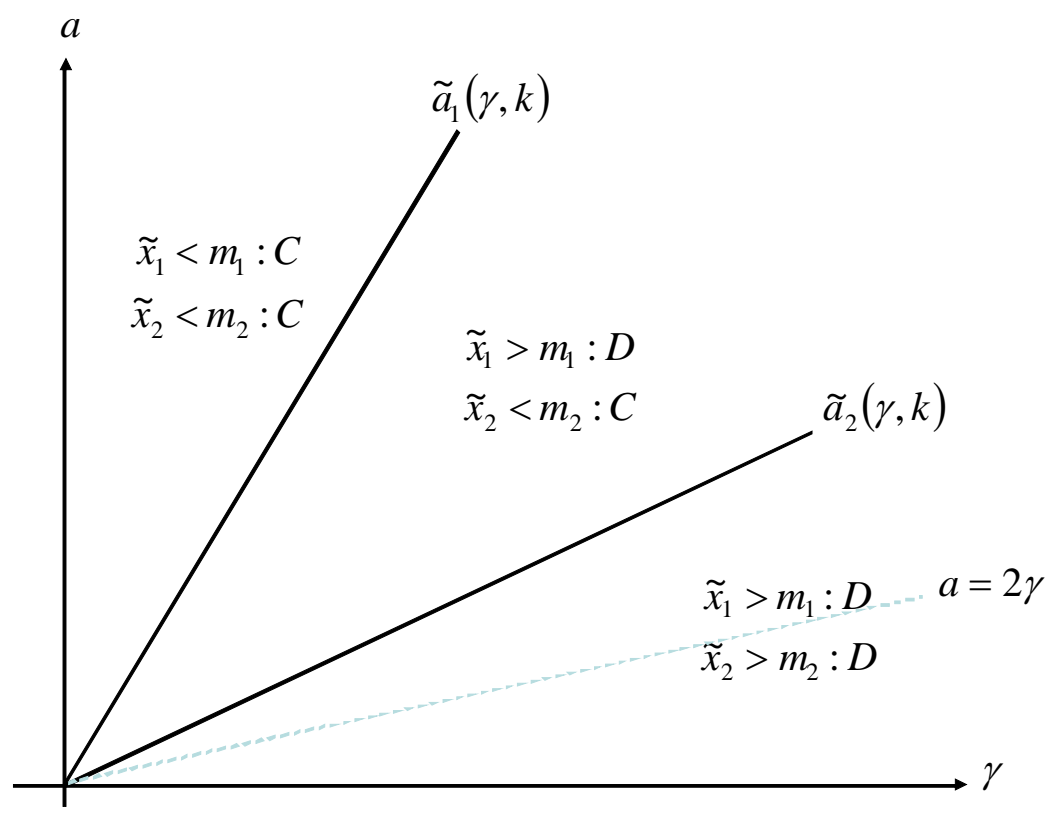

